\title{
Editorial on implementation of CT-based screening of lung cancer
}

This Translational Lung Cancer Research (TLCR) special series on "Implementation of lung cancer CT-based screening" appears when the COVID-19 epidemic dominates all medical topics in the modern world, pushing them back. It is also not an ideal time to deal with a screening. For example, in Poland, where the national pilot screening program began in January this year, its execution in March was stopped for five months, to be restarted again in August. When studies were resumed, one-third of registered studies were canceled by participants because of fear of infection. The same happened in other European countries where similar programs were started.

Such decisions of institutions responsible for introducing screening are understandable, however, it requires constant modification in connection with the evolution of the epidemic intensity and the possibility of safe conduct of radiological examinations and their assessment in compliance with the principles of social distancing.

In the beginning of COVID-19 pandemic several notable journals and societies issued guidelines for lung cancer screening and treatment of early lung cancer suggesting discontinuation of screening, diagnosis and treatment during the epidemic. To date, over time, several of them changed their recommendations, adjusting them to the dynamically changing epidemiological situation but in some cases no modification of this position has appeared, despite the fact that the epidemic situation is evolving. In my opinion, implementing such recommendations would represent a huge step back in the idea of early detection and local treatment of lung cancer patients. Norman Sharpless, who is a director of NCI, modeling the effect of Covid-19 on cancer screening and treatment for breast and colon cancer estimated 10,000 deaths excess from these cancers in the next decade due to delays in screening, detection, and treatment. Consequently, the number of lung cancer deaths will be double fold due to delays in diagnosis and early detection. In this context, we must remember that each year nearly two million people are dying of lung cancer while in 20201,78 million of SARS-CoV-2 infection.

But regardless of adversity, lung cancer screening using LDCT has become a reality in several European countries after the publication of the Nelson study. Thus, Europe joins the US in implementing screening, which is a milestone in the fight against lung cancer. This is good news, of course, however, when organizing such programs, we must answer a few or even a dozen important questions and solve a number of difficult issues, all about-how to organize screening? In the USA, a dispersed model was chosen, which allows testing in all medical units declaring such readiness. In Europe, a rather centralist model dominates, in which screening can take place in multidisciplinary centers that are appointed as coordinating institutions. This model allows CT scans to be performed in radiology facilities in various places, however, radiological images are interpreted in the central institutions ("central reading") as well as decisions in multidisciplinary teams, diagnostics and treatment of detected nodules. So, there are different screening models and time will show which one is superior. Therefore, we are dealing with a young branch of medicine, which is just gathering momentum and in which a number of problems are only being solved.

Increasing amounts of epidemiological, clinical, imaging, and molecular data are accumulating to allow research based on separate or pooled datasets to detect optimal risk assessment, radiomic, molecular or combined signature of early lung cancer. An IASLC-based initiative is being developed, called ELIC, which collects the largest collections of images of LDCT lung cancer screening participants. Analysis of such registers gives the possibility of using AI to conduct research, which is discussed in two chapters of this series. In addition to visualizing lung nodules, LDCT gives the opportunity to assess coronary artery calcification, aorta, and the severity of emphysema, or so-called "BIG 3", as well as assess other chest and epigastric pathologies, as Henschke et al. discusses.

At this moment we are facing practical phase of implementation process in Europe. In this special series, a group of the most outstanding experts and researchers of all aspects of lung cancer screening answers the most important questions about the introduction of a screening program as well as the development of this new field of medicine. Firstly, as mentioned the strategy of radiological and multidisciplinary evaluation-so the central or dispersed model of screening. Additionally, which risk assessment model and smoking cessation strategy should be applied. Secondly set up CT machines in order to supply the minimal radiation dose to participant with maximal quality assurance, concerning possibility of emphysema and vascular calcification assessment. And thirdly how to support all parties participated in screening beginning from family 
doctors and nurses and ended up on radiologists, pulmonologists and surgeons-so namely how to build the effective and simple networking system available for all mentioned stakeholders of the screening program. And how to collect all information in one database both for epidemiological data as well as for radiological images in the GDPR era. So, the target in the form of effective screening program seems to be so close, but yet it is so far. Therefore, the implementation process should be accompanied or surrounded by informatics, mathematicians and technological institutions and companies to build all supportive programs and software's facilitating lung cancer screening at all levels just making it simple and clear for all engaged parties and thus effective for participants. It seems to be complicated but this process has already been going on in all sites where lung cancer screening is going to be implemented. And the progress is huge not only in the screening process but also in all concomitant fields of medicine.

Most of aforementioned areas of interest are covered in this special series by specialists involved in the practical part of lung cancer screening implementation.

\section{Acknowledgments}

Funding: None.

\section{Footnote}

Provenance and Peer Review: This article was commissioned by the editorial office, Translational Lung Cancer Research for the series "Implementation of CT-based screening of lung cancer". The article did not undergo external peer review.

Conflicts of Interest: The author has completed the ICMJE uniform disclosure form (available at http://dx.doi.org/10.21037/ tlcr-2020-cts-14). The series "Implementation of CT-based screening of lung cancer" was commissioned by the editorial office without any funding or sponsorship. Dr. WR served as the unpaid Guest Editor of the series and serves as an unpaid editorial board member of Translational Lung Cancer Research from Jul 2019 to Jul 2021. Dr. WR reports other from Medtronic, outside the submitted work. The author has no other conflicts of interest to declare.

Ethical Statement: The author is accountable for all aspects of the work in ensuring that questions related to the accuracy or integrity of any part of the work are appropriately investigated and resolved.

Open Access Statement: This is an Open Access article distributed in accordance with the Creative Commons AttributionNonCommercial-NoDerivs 4.0 International License (CC BY-NC-ND 4.0), which permits the non-commercial replication and distribution of the article with the strict proviso that no changes or edits are made and the original work is properly cited (including links to both the formal publication through the relevant DOI and the license). See: https://creativecommons.org/licenses/by-nc$\mathrm{nd} / 4.0 /$. 


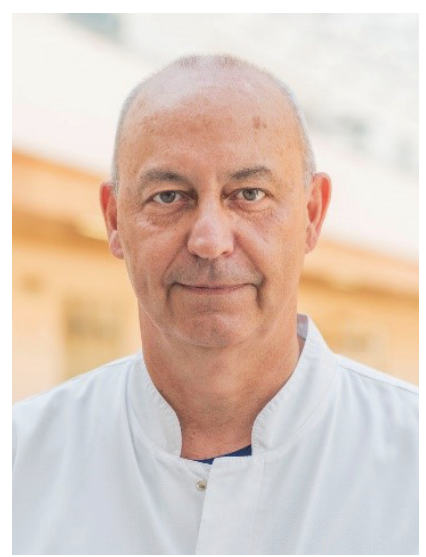

Witold Rzyman

Witold Rzyman

Department of Thoracic Surgery, Medical University of Gdansk, Gdansk, Poland.

(Email:wrzyman@gumed.edu.pl)

Submitted Dec 29, 2020. Accepted for publication Jan 08, 2021. doi: $10.21037 /$ tlcr-2020-cts-14

View this article at: http://dx.doi.org/10.21037/tlcr-2020-cts-14

Cite this article as: Rzyman W. Editorial on implementation of CT-based screening of lung cancer. Transl Lung Cancer Res 2021;10(2):1047-1049. doi: 10.21037/tlcr-2020-cts-14 